\title{
Adsorption of Algerian Asphaltenes onto Synthesized Maghemite Iron Oxide Nanoparticles
}

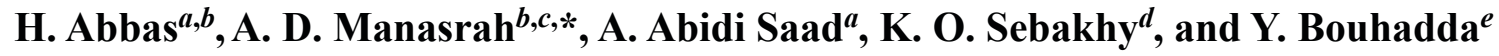 \\ ${ }^{a}$ Laboratoire de géologie du Sahara, Université Kasdi Merbah Ouargla, Ouargla, 30000 Algeria \\ ${ }^{b}$ Department of Chemical and Petroleum Engineering, University of Calgary, Calgary, T2N1N4 Canada \\ ${ }^{c}$ Carbon OxyTech Inc. Calgary, Alberta, T2L1Y8 Canada \\ ${ }^{d}$ Department of Chemical Engineering, Engineering and Technology Institute Groningen (ENTEG), University of Groningen, \\ Groningen, 9747 Netherlands \\ ${ }^{e}$ Laboratoire de Chimie physique des Macromolécules et interfaces biologiques, Mascara, 29000 Algeria \\ *e-mail:manasrah@carbonoxytech.com
}

Received April 28, 2020; revised July 24, 2020; accepted September 18, 2020

\begin{abstract}
In this study, the adsorption of Algerian asphaltene sample extracted from Hassi Messaoud oil field is conducted for the first time. The adsorption process was performed using novel synthesized iron oxide nanoparticles $\left(\gamma-\mathrm{Fe}_{2} \mathrm{O}_{3}\right) \cdot \gamma-\mathrm{Fe}_{2} \mathrm{O}_{3}$ Nanoparticles were in-house synthesized and characterized by an array of techniques using, Brunauer-Emmett-Teller (BET), high-resolution transmission electron microscopy (HRTEM) and X-ray diffraction (XRD). The results showed that the synthesized nanoparticles have an average crystalline domain size around $10 \mathrm{~nm}$ and a specific surface area of $120 \mathrm{~m}^{2} / \mathrm{g}$. The adsorption process of the Algerian asphaltenes took place in a batch mode by dissolving the asphaltenes in toluene at $25^{\circ} \mathrm{C}$. Different initial concentrations of asphaltene solutions were used in this study, namely 100,500 , and $1000 \mathrm{ppm}$. During this adsorption, both isotherm and kinetic studies were investigated. The results showed that the synthesized iron oxide nanoparticles are promising nano-adsorbents that have a high affinity to remove the asphaltenes and the equilibrium was recorded after $15 \mathrm{~min}$. The Solid-Liquid-Equilibrium (SLE) model was used to correlate the adsorption experimental data.
\end{abstract}

Keywords: Algerian asphaltenes, adsorption, iron oxide, nanoparticles, Solid-Liquid-Equilibrium

DOI: $10.1134 / \mathrm{S} 0965544121010072$

\section{INTRODUCTION}

Asphaltenes are the heaviest molecular weight components that are found in crude oil, along with saturates, aromatic and resins, which are soluble in toluene and insoluble in $n$-heptane [1-3]. The presence of asphaltenes in oil poses serious problems during oil recovery which is a major concern in all the world's oil fields $[4,5]$. One of these popular oil fields that encounter asphaltene deposition is Hassi Messaoud which is located in southern Algeria [1]. Indeed, as a result of asphaltenes deposition and precipitation, many oil wells have been entirely shut down in this oil field [6]. Currently, the remediation of asphaltenes includes several methods such as mechanical scratch treatment, tube coating, hot fluid removal, and solvent cleaning [7]. However, these classical techniques remain inefficient in asphaltenes removal. Recently, nanotechnology using novel nanoparticles has been considered to be an emerging technique with potential applications in the oil industry
$[8,9]$. Metal oxide nanoparticles like iron oxides, for instance, are one of particular interest because they tend to associate with asphaltene molecular aggregates and can behave as efficient nanoadsorbents $[10,11]$. A recent study on Hamaca asphaltenes adsorption showed that iron oxide had an uptake of 3.5 to $4 \mathrm{mg}$ asphaltenes $/ \mathrm{m}^{2}$ at a temperature near to room temperature using a high dosage of adsorbent (50 to $30 \mathrm{~g} / \mathrm{L}$ ) [10]. Impregnation of $\mathrm{Fe}_{2} \mathrm{O}_{3}$ on the surface of kaolinite, carbon nanotubes (CNT), montmorillonite and $\mathrm{SiO}_{2}$ strongly improved the adsorption capacity relative to the surfaces of unmodified sorbent bases [12, 13]. Nassar et al. for instance, used six different metal oxide nanoparticles for the adsorption and oxidation of asphaltenes, namely $\mathrm{Fe}_{3} \mathrm{O}_{4}, \mathrm{Co}_{3} \mathrm{O}_{4}, \mathrm{TiO}_{2}$, $\mathrm{MgO}, \mathrm{CaO}$, and $\mathrm{NiO}[14,15]$. The results showed that the adsorption of asphaltenes was affected by the types of metal oxides and the asphaltenes uptake followed the order $\mathrm{CaO}>\mathrm{Co}_{3} \mathrm{O}_{4}>\mathrm{Fe}_{3} \mathrm{O}_{4}>\mathrm{MgO}>\mathrm{NiO}>\mathrm{TiO}$. Additionally, iron oxide nanoparticles have shown also 
to be an excellent adsorbent and a catalyst for catalytic oxidation of thermally cracked asphaltenes [14]. In another study, magnetic iron oxide nanoparticles capped with sulfonated asphaltenes have been proposed as natural and inexpensive materials that could act as oil collectors for Arabian heavy crude oil [16]. In that study, three types of metal oxide nanoparticles were considered for asphaltenes oxidation, namely: $\mathrm{NiO}, \mathrm{Co}_{3} \mathrm{O}_{4}$, and $\mathrm{Fe}_{3} \mathrm{O}_{4}$, and the results showed that the presence of nanoparticles decreases the activation energy of asphaltenes oxidation and increases the rate of reaction [17]. The impact of iron oxide nanoparticles on the precipitation of asphaltenes during $\mathrm{CO}_{2}$ injection was studied by Kazemzadeh et al. [18]. The synthesized maghemite $\left(\gamma-\mathrm{Fe}_{2} \mathrm{O}_{3}\right)$ and hematite $\left(\alpha-\mathrm{Fe}_{2} \mathrm{O}_{3}\right)$ nanoparticles were used for the adsorption and elimination of asphaltenes. The reported results showed that the maximum adsorption capacity of maghemite and hematite was 108.1 and $45.8 \mathrm{mg} / \mathrm{g}$, respectively. Maghemite and hematite could be used as nanoadsorbents of asphaltenes, where the maghemite is more effective towards their adsorption [19]. Moreover, Franco et al. studied the effect of resins on the adsorption behavior of $n-\mathrm{C}_{7}$ asphaltenes on silica and hematite nanoparticles [20]. The results indicated that resin had no significant influence on the adsorbed amount of asphaltenes, which showed that resin I has a solvent-like behavior, such as toluene, mainly at low concentrations $(<3000 \mathrm{mg} / \mathrm{L})$ [20].

However, despite these exertions attempting to eliminate or prohibit asphaltenes precipitation, these challenges remain open and unsolved, especially for Algerian asphaltenes. This because the asphaltenes precipitation is among the most important challenges in Algerian oil fields which significantly affect oil recovery. It should be noted here that Algeria is among the world giants in the hydrocarbons sector, especially in Hassi Messaoud oil field. This oil field is the largest oil deposits in Algeria discovered in $1956\left(2500 \mathrm{~km}^{2}\right)$ and contains about $71 \%$ of proved reserves in Algeria [21]. In fact, with this field; Algeria is classified as the third in Africa continent and the 16th amongst more than 55 countries in the world regarding oil resources [22]. It produces up to 65.3 million tonnes of oil and 12.2 billion barrels of proved oil reserves for 2018 [22]. Based on the literature survey it seems clear that no work has been conducted to treat the asphaltenes problems using adsorption with nanoparticles in Hassi Messaoud oil field. Thus, accordingly, at the level of the author's knowledge, it is the first time that such a study focuses on the adsorption of the asphaltenes contained in the Algerian crude oil using such novel synthesized maghemite iron oxide $\left(\gamma-\mathrm{Fe}_{2} \mathrm{O}_{3}\right)$ nanoparticles. Herein, in the present study, the adsorption of Algerian asphaltenes from Hassi Messaoud onto novel improved maghemite iron oxide $\left(\gamma-\mathrm{Fe}_{2} \mathrm{O}_{3}\right)$ nanoparticles was investigated. The nanoparticles were prepared and routinely characterized using HRTEM, BET and XRD techniques. The nanoparticles used in this study are proposed as potential candidates for asphaltenes elimination from Algerian crude oils. This approach of asphaltenes uptake by nanoparticles shall extensively improve the oil recovery and minimize the problematic issues caused by asphaltenes aggregation and precipitation.

\section{EXPERIMENTAL}

Materials. An oil sample was obtained from Hassi Messaoud oil field and employed to extract the asphaltenes. $n$-heptane (99\%) was used as a solvent for asphaltenes extraction from Algerian light oil and toluene HPLC grade was used as a solvent to solubilize the asphaltene sample. Both solvents were obtained from Sigma-Aldrich, Ontario, Canada and used as received. Table S1 in the Supplementary Materials provides a full saturates, aromatics, resins, asphaltenes (SARA) analysis of the oil. For $\gamma-\mathrm{Fe}_{2} \mathrm{O}_{3}$ nanoparticles preparation, the following chemicals and reagents were used, ammonium iron(II) sulfate hexahydrate $\left(\mathrm{NH}_{4}\right)_{2} \mathrm{Fe}\left(\mathrm{SO}_{4}\right)_{2} \cdot 6 \mathrm{H}_{2} \mathrm{O}$, ammonium hydroxide solution $(26 \%) \mathrm{NH}_{4} \mathrm{OH}$, hydrogen peroxide $\left(\mathrm{H}_{2} \mathrm{O}_{2}, 30 \mathrm{wt} \%\right)$, and nitric acid $\left(\mathrm{HNO}_{3}\right)$. All of these materials were received from Sigma-Aldric, Ontario, Canada and used without further modifications.

Extraction of asphaltenes. Asphaltenes were extracted from the Algerian Hassi Messaoud oil field following the standard method ASTM D6560 (i.e., 1 : 40 oil/solvent ratio) [23]. The extraction process was carried out by adding $n$-heptane to the oil well sample with an oil/solvent ratio $(\mathrm{O} / \mathrm{S})$ of $1: 40(\mathrm{~g} / \mathrm{mL})$. The resulting mixture was heated to $90^{\circ} \mathrm{C}$ in a flask. After that, the mixture was sonicated for $45 \mathrm{~min}$ at room temperature for stabilization. The solution was then filtered using a $0.45 \mu \mathrm{m}$ pore diameter filter paper [24]. The precipitated asphaltenes were washed with $n$-heptane at a ratio of $1: 5(\mathrm{~g} / \mathrm{mL})(\mathrm{O} / \mathrm{S})$ in a Soxhlet apparatus until the filtrate became colorless. Finally, the filtered asphaltenes were dried overnight under vacuum at $80^{\circ} \mathrm{C}$.

Preparation of maghemite iron oxide nanoparticles $\left(\gamma-\mathrm{Fe}_{2} \mathrm{O}_{3}\right)$. The $\gamma-\mathrm{Fe}_{2} \mathrm{O}_{3}$ nanoparticles were in-housed

PETROLEUM CHEMISTRY Vol. 61 No. 12021 
prepared using the precipitation method at room temperature [25]. The preparation method was firstly started by dissolving $6 \mathrm{~g}\left(\mathrm{NH}_{4}\right)_{2} \mathrm{Fe}\left(\mathrm{SO}_{4}\right)_{2} \cdot 6 \mathrm{H}_{2} \mathrm{O}$ in $100 \mathrm{~mL}$ of deionized water (DIW). After complete dissolution of the iron salt ( $\sim 5 \mathrm{~min}), 5 \mathrm{~mL}$ of $\mathrm{NH}_{4} \mathrm{OH}$ solution (26\%) was added dropwise at a rate of $1 \mathrm{~cm}^{3} / \mathrm{s}$ using a syringe pump. Subsequently, 15 drops of $\mathrm{H}_{2} \mathrm{O}_{2}$ (30 wt \%) were added to the solution to partially oxidize part of the $\mathrm{Fe}^{2+}$ to $\mathrm{Fe}^{3+}$ and thus producing a precipitated black nanocrystalline of $\mathrm{Fe}_{3} \mathrm{O}_{4}$. After that, vacuum filtration and washing were performed using 300$400 \mathrm{~mL}$ DIW at room temperature. The produced black materialwas allowed to dry under vacuum overnight. The next day, the dried $\mathrm{Fe}_{3} \mathrm{O}_{4}$ nanomaterial was calcined in an oven at $250^{\circ} \mathrm{C}$ for $2 \mathrm{~h}$. This step is important to release some hydroxyl ions $\left({ }^{-} \mathrm{OH}\right)$ from the surface and to oxidize the $\mathrm{Fe}^{2+}$ remaining in the magnetite to produce the desired maghemite. Then, the obtained sample was immersed in the acidic medium $\left(\mathrm{HNO}_{3}\right)$ to remove any excess $\mathrm{Fe}^{3+}$ produced during the transformation of magnetite into maghemite. A suspension of $3 \mathrm{~g} / \mathrm{L}$ of nano- $\gamma-\mathrm{Fe}_{2} \mathrm{O}_{3}$ in DIW was prepared, and the $\mathrm{pH}$ of this suspension was adjusted to 3 using $0.10 \mathrm{M} \mathrm{HNO}_{3}$ acid. The solution was kept for at least $5 \mathrm{~min}$ at $\mathrm{pH}$ of 3 . Then, the temperature was increased up to $90^{\circ} \mathrm{C}$ and kept for 30 min under magnetic stirring (300-400 rpm). Finally, the sample was filtered, washed with DIW and dried to produce $\mathrm{Fe}_{2} \mathrm{O}_{3}$ adsorbent nanoparticles [26].

Characterization of maghemite nanoparticles $\left(\gamma-\mathrm{Fe}_{2} \mathrm{O}_{3}\right)$. The crystalline domain structures and sizes of the as-prepared $\gamma-\mathrm{Fe}_{2} \mathrm{O}_{3}$ nanoparticles were determined using an Ultima III multi-purpose diffraction system (Rigaku Corp., The Woodlands, TX) with $\mathrm{Cu} K_{\alpha}$ radiation operating at $40 \mathrm{kV}$ and $44 \mathrm{DmA}$ and scan range of $3^{\circ}-90^{\circ}$ $2 \theta$ using a $0.05^{\circ}$ degree and a counting time of $0.2^{\circ} / \mathrm{min}$. The average crystalline domain sizes were measured using the Debye-Scherrer equation [Eq. (1)] [19] implemented in JADE commercial software (supplied with the diffractometer) by calculating the full width at half height, full width at half-maximum (FWHM) peaks corresponding to the experimental profile to a pseudoVoigt profile function.

$$
D=\frac{K \lambda}{\beta \cos \theta},
$$

where $K=0.9$ is Scherrer's constant, $\lambda=0.154 \mathrm{~nm}$ is the wavelength of X-rays, $\theta$ is the diffraction angle in degrees, and $\beta$ is the width of the peak at the half-maximal height of the peak.
The surface area and pore size distributions were measured using Brunauer-Emmett-Teller (BET) method by performing nitrogen physisorption at $-196^{\circ} \mathrm{C}$ using a porosity analyzer and TriStar II 3020 specific surface area (Micrometrics Instrument Corporation, Norcross, GA). The sample was firstly degassed at $150^{\circ} \mathrm{C}$ under $\mathrm{N}_{2}$ flow overnight to remove any existing moisture. Particle size was calculated with the BET surface area according to Eq. (2):

$$
d=\frac{6000}{\left(S A \cdot \rho_{\mathrm{mag}}\right)},
$$

where $d$ is the particle size in nm, $S A$ is the experimentally measured surface area $\left(\mathrm{m}^{2} / \mathrm{g}\right)$, and $\rho_{\text {mag }}$ is the density of maghemite $\left(4.9 \mathrm{~g} / \mathrm{cm}^{3}\right)$.

The surface morphology of the nanoparticles was also analyzed by FEI Tecnai F20 FEG Transmission electron microscopy (TEM) using a $200 \mathrm{kV}$ acceleration voltage. About $0.5 \mathrm{mg}$ of nanoparticles were dispersed in $1 \mathrm{~mL}$ of pure ethanol, and then a drop of the solution was deposited on the sample holder. After evaporating the ethanol, the dried powder, on the grid support, is ready for imaging.

Adsorption experiments. Adsorption kinetic experiments. Adsorption kinetic experiments were carried out with a UV-Vis spectrophotometer (Nicolet Evolution 100, Thermo Instruments Canada, Inc., Mississauga, Ontario, Canada). Three initial concentrations of asphaltenes of 100,500 , and $1000 \mathrm{mg} / \mathrm{L}$ were prepared, and the temperature of the solution was $25^{\circ} \mathrm{C} .10 \mathrm{~mL}$ of asphaltenes-toluene solution at a ratio of $1: 10(\mathrm{~L} / \mathrm{g})$ asphaltenes mass solution/nanoparticle was used. The sample was shaken using a Wrist Action (Burrel, Model 75-BB) shaker, and thus the change of absorbance for asphaltenes in the supernatant was recorded continuously up to $4 \mathrm{~h}$. The kinetic curves were plotted as a function of time of 1-150 min, especially the amount adsorbed increased rapidly during the first $15 \mathrm{~min}$ and remained unchanged after $60 \mathrm{~min}$ of contact.

Equilibrium adsorption isotherms. The batch adsorption experiments were carried out at a temperature of $25^{\circ} \mathrm{C}$ by preparing different solutions of asphaltenes, dissolved in toluene. All adsorption experiments were conducted in $10 \mathrm{~mL}$ of asphaltenes-toluene solution at a ratio of $1: 10(\mathrm{~L} / \mathrm{g})$ asphaltenes mass solution/ nanoparticle. The tested vials were sealed firmly to prevent toluene evaporation. The adsorption was allowed to proceed by shaking the flasks for $24 \mathrm{~h}$ on a Wrist Action (Burrel, Model 75-BB) shaker, ensuring equilibrium was achieved. Then, the nanoparticles containing asphaltenes 


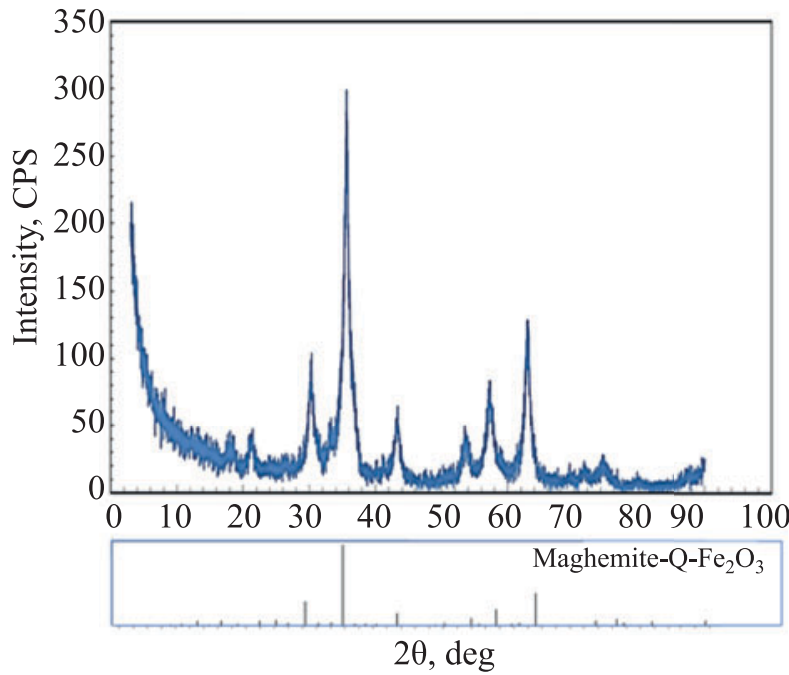

Fig. 1. X-ray diffraction pattern of synthesized $\gamma-\mathrm{Fe}_{2} \mathrm{O}_{3}$ nanoparticles (blue lines). The vertical lines (black color) are the reference COD database of Maghemite-Q- $\mathrm{Fe}_{2} \mathrm{O}_{3}$ (01-0764113 ICDD 2005).

were separated by centrifugation at $5000 \mathrm{rpm}$ for $30 \mathrm{~min}$. The concentrations of asphaltenes in the solution were evaluated using a UV-Vis spectrophotometer (Nicolet Evolution 100, Thermo Instruments Canada, Inc., Mississauga, Ontario, Canada). The calibration curve was constructed at a wavelength of $298 \mathrm{~nm}$. The selected experiments were repeated twice to confirm their reproducibility. The adsorption of asphaltenes onto iron oxide nanoparticles was determined from the change in the concentration of asphaltenes in the model oil solution, before and after mixing with the nanoparticles. The adsorbed amount of $n-\mathrm{C}_{7}$ asphaltenes $\left(\mathrm{mg} / \mathrm{m}^{2}\right)$ was calculated based on the mass balance analysis, as indicated in Eq. (3):

$$
Q=\frac{\left(c_{0}-c_{\mathrm{e}}\right) V}{S A \cdot m},
$$

where $c_{0}$ is the initial concentration of $n-\mathrm{C}_{7}$ asphaltenes in solution $(\mathrm{mg} / \mathrm{L}), c_{\mathrm{e}}$ is the equilibrium concentration of $n-\mathrm{C}_{7}$ asphaltenes in the supernatant $(\mathrm{mg} / \mathrm{L}), V$ is the

Table 1. Textural properties and average particle size of $\gamma-\mathrm{Fe}_{2} \mathrm{O}_{3}$ nanoparticles

\begin{tabular}{l|c}
\hline \multicolumn{1}{c|}{ The chemical formula of iron oxide } & Value \\
\hline BET specific surface area, $\mathrm{m}^{2} / \mathrm{g}$ & $120 \pm 3$ \\
t-plot Micropore Area, $\mathrm{m}^{2} / \mathrm{g}$ & $6 \pm 1.5$ \\
External surface, $\mathrm{t}-\mathrm{plot}, \mathrm{m}^{2} / \mathrm{g}$ & $114 \pm 5$ \\
BJH Pore Volume, $\mathrm{cm}^{3} / \mathrm{g}$ & 0.29 \\
BJH Average Pore Width, $\AA$ & 82.7 \\
Particle size measured by XRD, nm & $10 \pm 2$ \\
Estimated particle size using the BET, nm & 10 \\
\hline
\end{tabular}

volume of solution (L), $S A$ is the BET surface area of the $\gamma-\mathrm{Fe}_{2} \mathrm{O}_{3}$ prepared nanoparticles $\left(\mathrm{m}^{2} / \mathrm{g}\right)$, and $m$ is the mass of the nanoparticles $(\mathrm{g})$.

\section{RESULTS AND DISCUSSIONS}

Characterization of $\gamma-\mathrm{Fe}_{2} \mathrm{O}_{3}$ nanoparticles. The crystalline structure, particle size and specific surface area of the prepared nanoparticles $\left(\gamma-\mathrm{Fe}_{2} \mathrm{O}_{3}\right)$ were measured and summarized in Table 1. As shown in the table, after measuring the specific surface area using BET equation $\left(120 \mathrm{~m}^{2} / \mathrm{g}\right)$ and the external surface using the $\mathrm{t}$-plot method $\left(114 \mathrm{~m}^{2} / \mathrm{g}\right)$, there is no significant difference observed between values, thus suggesting that the prepared iron oxide nanoparticles are non or macroporous and maintaining a high external surface area [27]. Nitrogen adsorption-desorption isotherms for iron oxide nanoparticles, provided in the Supplementary Materials (Fig. S1), follows the isotherms type II according to the IUPAC classification, for macropore solids [28]. To get more information about the accessible surface area, one the most important parameters that plays an important role on the reactivity of the materials for the adsorption of asphaltenes, the estimated pore diameters using the Barrett-Joynes-Halenda (BJH) method ranged from $20 \AA$ to more than one hundred nanometers with a sharp peak at $82 \AA$, as shown in (Fig. S2) in the Supplementary Materials. At the pore size distribution below $50 \AA$, the micro and mesoporosity can barely observed and their contribution is very small. The surface area microporous area (t-plot Micropore Area) was around $6 \mathrm{~m}^{2} / \mathrm{g}$. On the other hand, a significant contribution to pore size distribution can be observed above $50 \AA$, indicating for the macro-porosity of the material. Accordingly, the asprepared nanoparticle has great potential to accommodate large molecules such as asphaltenes. In addition, for purposes of comparison with the measured XRD particle size, the particle size (assuming spherical particles) was also calculated based on the surface area measurements, as previously explained in Eq. (2). Thus, the obtained value for $d$ agrees well with the one obtained by XRD, indicating that the material may indeed be composed of spherical-type nanoparticles. Figure 1 shows the $\mathrm{X}$-ray diffractogram of the $\gamma-\mathrm{Fe}_{2} \mathrm{O}_{3}$ nanoparticles. The identification of the pattern confirms that the material is maghemite, as reported by the preparation protocol. The structure was identified by comparing the XRD signals with those reported in the pdf map 01-076-4113 ICDD 2005 (International Center for Diffraction Data) database included in the JADE V.7.5.1 software. As seen 


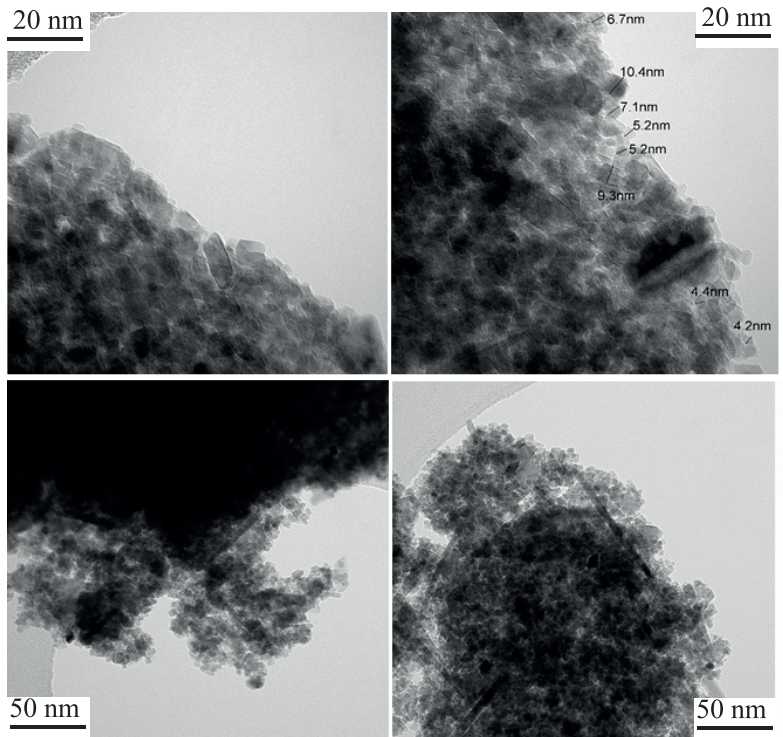

Fig. 2. HRTEM images for the $\gamma-\mathrm{Fe}_{2} \mathrm{O}_{3}$ studied nanoparticles (the line mark in the images corresponds to 20 and $50 \mathrm{~nm}$ ).

from Fig. 1, the peaks are very broad indicating very small crystalline domain sizes for the used $\gamma-\mathrm{Fe}_{2} \mathrm{O}_{3}$. The presence of the tetragonal vacancy-ordered superstructure in these nanoparticles is clearly marked by the appearance of weak XRD signals a $2 \theta \mathrm{Cu} K_{\alpha}$ of $15^{\circ}, 24^{\circ}$, and $26^{\circ}$.

To gain a better understanding of the morphology and size of $\gamma-\mathrm{Fe}_{2} \mathrm{O}_{3}$ nanoparticles used in this study, HRTEM images are depicted in (Fig. 2), which confirms the presence of nanometric particles of $\gamma-\mathrm{Fe}_{2} \mathrm{O}_{3}$. Most of the nanoparticles are spherical with diameters range between 4 and $11 \mathrm{~nm}$, while some are in the form of short clusters. Large aggregates of particles allowed observation of morphology types and measurement of individual sizes when autonomous nanoparticles were expelled by the electron beam when an attempt was made to analyze them.

Adsorption of asphaltenes onto $\boldsymbol{\gamma}-\mathrm{Fe}_{2} \mathrm{O}_{3}$ nanoparticles. Kinetics of adsorption. Figure 3 shows the change in the amount of asphaltenes adsorbed as a function of contact time. In all cases $(100,500$, and $1000 \mathrm{ppm}$ ), the amount of asphaltenes adsorbed was rapidly increased in the first $15 \mathrm{~min}$ and remained unchanged after $60 \mathrm{~min}$ of contact. This indicates that steady-state was almost reached within $15 \mathrm{~min}$. This rapid adsorption of asphaltenes is certainly linked to the high degree of dispersion of the nanoparticles as well as to the great availability of the external surface because the $\gamma-\mathrm{Fe}_{2} \mathrm{O}_{3}$ selected is a non-porous adsorbent $[14,15]$. Therefore, it takes a short time to adsorb the molecules, because of the lack of intra-particle diffusion
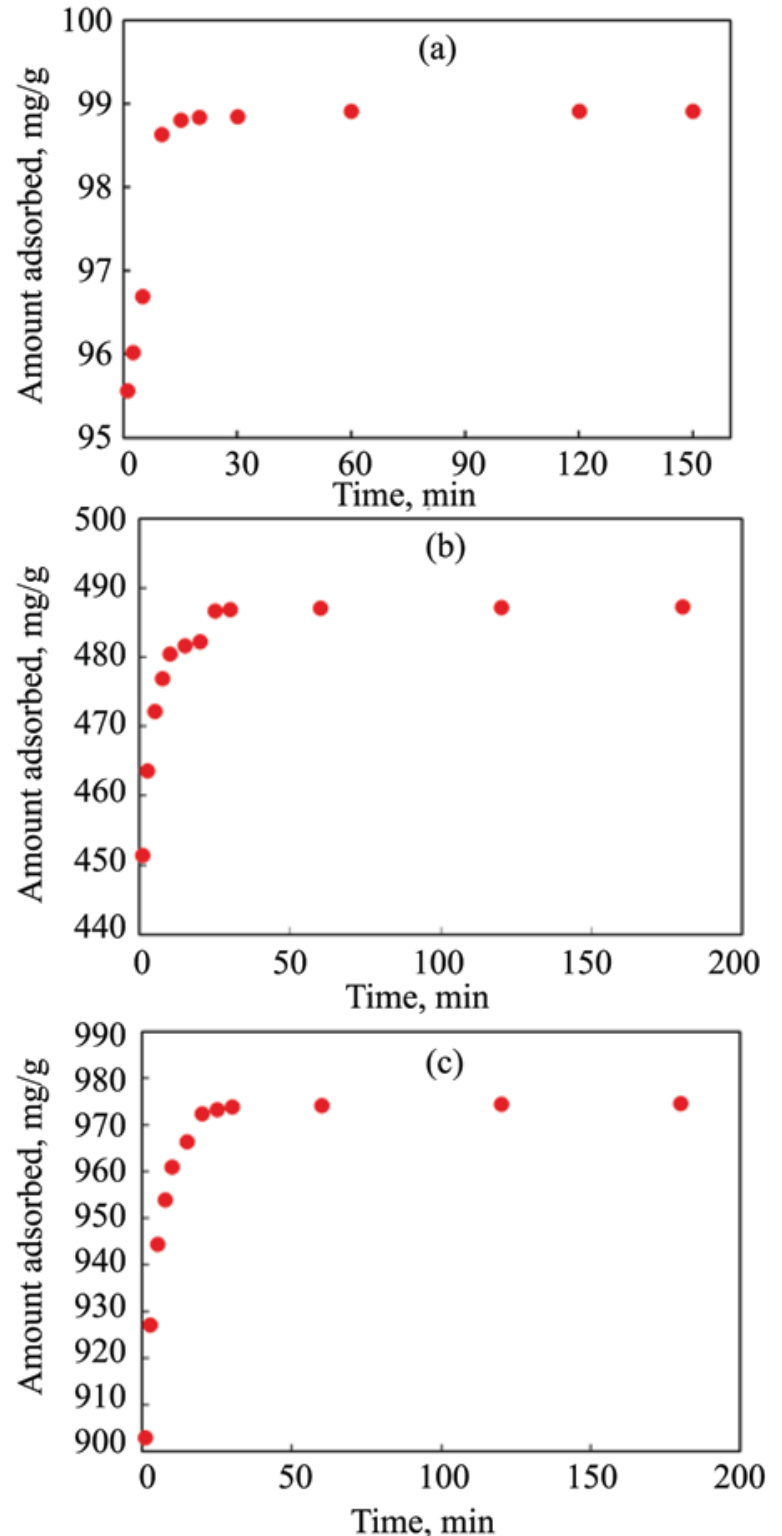

Fig. 3. Kinetics of asphaltenes adsorption onto nanoparticles of $\gamma-\mathrm{Fe}_{2} \mathrm{O}_{3}$ obtained at three initial concentrations of (a) 100, (b) 500 , and (c) $1000 \mathrm{ppm}$ at $25^{\circ} \mathrm{C}$.

which limits the adsorption rate. The equilibrium results are in agreement with what has been reported by Dr. Nassar group for the adsorption of asphaltenes on iron oxide nanoparticles [14]. However, it is different than the other conventional porous adsorbents, in which very slow adsorption of asphaltenes occurs through the pore diffusion steps, which in turn requires a longer equilibrium time $[29,30]$. It is noteworthy that the adsorption of asphaltenes onto surfaces of nanoparticles depends on the type and strength of interactions between the asphaltene species and the solid surface [9]. It was 


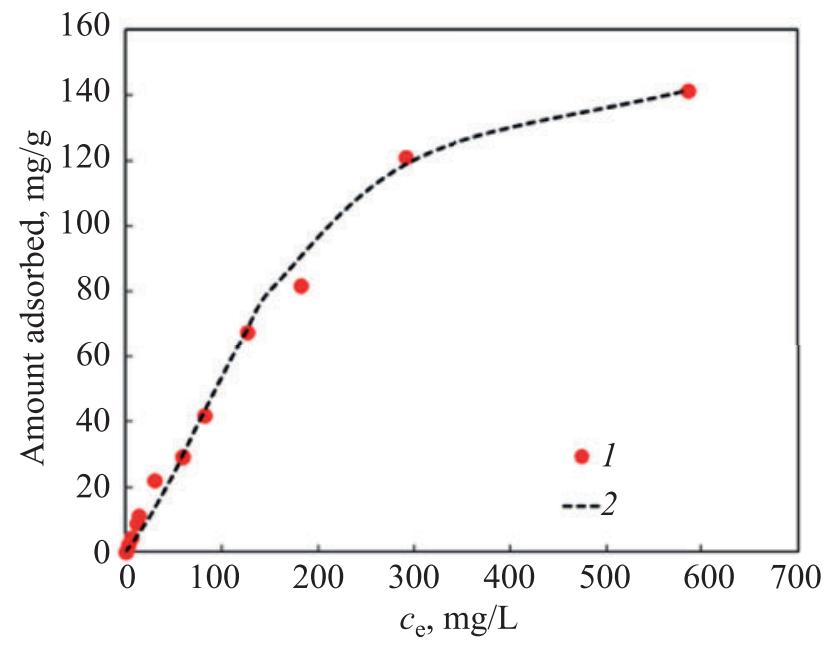

Fig. 4. Adsorption isotherm of asphaltenes on nanoparticles of $\gamma-\mathrm{Fe}_{2} \mathrm{O}_{3}$. Dosage of nanoparticles: $10 \mathrm{~g} / \mathrm{L}$; contact time: $24 \mathrm{~h}$; and temperature: $25^{\circ} \mathrm{C}$. (1) Experimental data and (2) prediction from the SLE model [Eq. (4)].

reported that there are a number of interparticle forces are responsible for successful interaction between nanoparticles and asphaltenes functionality groups such as carboxylic, pyrrolic, pyridininc, thiophenic, and sulfite groups [31,32]. The major forces that could contribute to these interactions are van der Waals, electrostatic, charge transfer, hydrogen bonding, and steric interactions [32]. The polar interactions, for example, are acid-base reactions occurring between adsorbate and adsorbent. However, in the case of iron oxide as a type of amphoteric oxides demonstrate higher adsorption capacity as compared with acidic oxides and similar to that of basic oxides. Similar observations were reported elsewhere for adsorption of asphaltenes onto different minerals and clays [33-36]. Mohammadi et al. [37], for instance, used different types of metal oxide nanoparticles, such as $\mathrm{SiO}_{2}, \mathrm{TiO}_{2}$, and $\mathrm{ZrO}_{2}$, for enhancing the stability of asphaltene nanoaggregates by forming hydrogen bonds at acidic conditions. The authors confirmed that $\mathrm{TiO}_{2}$ nanofluids, under strongly acidic conditions, might be acting as a dispersant, thereby enhancing the stability of the asphaltenes and leading to a higher precipitation onset point. Similarly, Hosseinpour et al. [3] reported the adsorption of asphaltene onto different acid/base metal

Table 2. SLE isotherm parameters for the asphaltenes adsorption onto nanoparticles of $\gamma-\mathrm{Fe}_{2} \mathrm{O}_{3}$ at a temperature of $25^{\circ} \mathrm{C}$

\begin{tabular}{c|c|c|c|c}
\hline \multicolumn{5}{c}{ SLE Parameters } \\
\hline$H, \mathrm{mg} / \mathrm{g}$ & $K, \mathrm{~g} / \mathrm{g}$ & $q_{\mathrm{m}}, \mathrm{mg} / \mathrm{m}^{2}$ & $R^{2}$ & $\chi^{2}$ \\
\hline 1.35 & $7.39 \mathrm{E}-03$ & 163.78 & 0.99 & 0.17 \\
\hline
\end{tabular}

oxides nanoparticles, such as $\mathrm{NiO}, \mathrm{Fe}_{2} \mathrm{O}_{3}, \mathrm{WO}_{3}, \mathrm{MgO}$, $\mathrm{CaCO}_{3}$, and $\mathrm{ZrO}_{2}$, and they found that the adsorption isotherms follow Langmuir-type behavior with an adsorption capacity of $1.23-3.67 \mathrm{mg} / \mathrm{m}^{2}$. In another study using palladium and nickel oxide incorporated into fumed silica nanoparticles, Franco et al. [38] reported a significant enhancement in the adsorption Colombian $n-\mathrm{C}_{7}$ asphaltenes.

Adsorption isotherm. Figure 4 shows the amount of asphaltenes adsorbed onto the nanoparticles as a function of the equilibrium concentration $\left(c_{\mathrm{e}}\right)$ at $25^{\circ} \mathrm{C}$. The figure shows that the adsorption of the studied asphaltenes increases at low concentration and begins to stabilize at a higher concentration, which suggests that $\gamma-\mathrm{Fe}_{2} \mathrm{O}_{3}$ nanoparticles have a good adsorption affinity for our asphaltenes. The adsorption isotherm profile (Fig. 4) is similar to a previous study on iron oxide nanoparticles for rapid adsorption of asphaltenes [14]. Nazila and Behruz confirmed that the maximum adsorption capacity of maghemite $\gamma-\mathrm{Fe}_{2} \mathrm{O}_{3}$ is greater than that of hematite $\left(\alpha-\mathrm{Fe}_{2} \mathrm{O}_{3}\right)$ [19].

The difference in adsorption capacity was attributed to the smaller size and larger surface area of maghemite compared to hematite [19]. Another important factor that may contribute to the adsorption capacity could be the acidity of the maghemite surface of $\gamma-\mathrm{Fe}_{2} \mathrm{O}_{3}$ [39]. To better understand this adsorption behavior, the experimental isotherm data were fitted to the SLE model (Solid-Liquid-Equilibrium) [40]. This model is based on the chemical theory for gas adsorption on solid at different load ranges, and thus it improves the understanding of asphaltenes aggregation and interactions onto the solid surface at equilibrium and provides a realistic representation of asphaltenes aggregation [41] as expressed by the following equation:

$$
c=\frac{\psi H}{1+K \psi} \exp \left(\frac{\psi}{q_{\mathrm{m}} A}\right),
$$

where

$$
\psi=\frac{-1+\sqrt{1+4 K \xi}}{2 K}, \xi=\left(\frac{q_{\mathrm{m}} q}{q_{\mathrm{m}}-q}\right) A,
$$

$q\left(\mathrm{mg} / \mathrm{m}^{2}\right)$ and $q_{\mathrm{m}}\left(\mathrm{mg} / \mathrm{m}^{2}\right)$ are the amounts of asphaltenes adsorbed on the surface of nanoparticles and the maximum adsorption capacity of the nanoparticles, respectively. $A\left(\mathrm{~m}^{2} / \mathrm{mg}\right)$ is the BET surface measured for the dried nanoparticles, and $c(\mathrm{mg} / \mathrm{L})$ is the equilibrium concentration of asphaltenes. The parameters of SLE model $K(\mathrm{~g} / \mathrm{g})$ and $H(\mathrm{mg} / \mathrm{g})$ are the adsorption constants 
related to the degree of self-association of asphaltenes on the surface of the nanoparticles and Henry's law constant related to asphaltene preference in adsorbed liquids, respectively [32]. The lower the value of $\mathrm{H}$, the higher the affinity for the adsorbed phase. However, the degree of asphaltenes aggregation at the adsorption site is higher as the $K$ value increases, thus affecting the degree of saturation of the adsorption site [35]. The SLE model parameters along with the correlation coefficient $\left(R^{2}\right)$ and the nonlinear analysis of the chi-squared $\left(\chi^{2}\right)$ were used to assess the fit quality of the SLE model to the experimental data are listed in Table 2. All analyses were performed using Data Fit software (version 8.2.79, Oakdale Engineering, Oakdale, PA, USA). As shown in (Fig. 4), an excellent agreement was obtained between the SLE model and the experimental data, which is also indicated by the values of $R^{2}$ (close to 1.0) and the low values of $\chi^{2}$ given in Table 2, which shows a strong tendency for asphaltene molecules to dimerize and aggregate. Consequently, it can be deduced that the adsorption of asphaltenes on the nanoparticles was multilayer adsorption. In other words, after the formation of the first layer, due to the high affinity of the asphaltene molecules for aggregation, the subsequent molecules are attached to the first layer and the multilayer adsorption takes place. The use of iron oxide nanoparticles for asphaltenes adsorption has been reported by many researcher groups. Nassar et al. [14], for instance, employed iron oxide nanoparticles, $43 \mathrm{mg} / \mathrm{m}^{2}$ surface area and $\sim 25 \mathrm{~nm}$ particle size, for $\mathrm{C}_{7}$-asphaltenes adsorption extracted from Athabasca vacuum residue. It was found that the maximum adsorption capacity was $1.7 \mathrm{mg} / \mathrm{m}^{2}$ using the Langmuir isotherm model. The authors confirmed that the adsorption mechanism is dominated by polar interactions between adsorbate and adsorbent [15]. In another study using maghemite and hematite iron oxide for Iranian asphaltenes, the results showed that maximum adsorption capacity is 108.1 and $45.8 \mathrm{mg} / \mathrm{g}$, respectively, using the SLE model [19]. Similarly, using Iranian asphaltenes, the maximum adsorption capacity of asphaltene onto $\mathrm{Fe}_{2} \mathrm{O}_{3}, 44 \mathrm{~nm}$ particle size, was $3.52 \mathrm{mg} / \mathrm{m}^{2}$ followed Langmuir-type behavior. In comparison, the prepared iron oxide nanoparticles, in this study, provided a higher surface area with a higher affinity toward Algerian asphaltenes adsorption compared to those reported iron oxide nanoparticles. These results obtained can support the objective of this study to synthesize and improve maghemite iron oxide to absorb solid asphaltenes.

\section{CONCLUSIONS}

A simple synthetic route was used to prepare $\gamma-\mathrm{Fe}_{2} \mathrm{O}_{3}$ nano-adsorbent and applied for the removal of asphaltenes in a toluene solution. The nanomaterial was routinely characterized, and the structure was confirmed. Unprecedented adsorption of asphaltenes was observed onto the $\gamma-\mathrm{Fe}_{2} \mathrm{O}_{3}$ nanoparticles. The iron oxide nanoparticles are promising nano-adsorbents that have a high affinity to remove the asphaltenes and the equilibrium was recorded after only $15 \mathrm{~min}$. The experimental adsorption isotherm matched well and showed a good fit to the SLE model. This study proposes the use of those nanomaterials as potential adsorbents for asphaltenes to avoid their precipitation in pipelines or auxiliary equipment during the transportation of Algerian Hassi Messaoud oil.

\section{ADDITIONAL INFORMATION}

H. Abbas, ORCID: http://orcid.org/0000-0001-7169-2030

A.D. Manasrah, ORCID: http://orcid.org/0000-0002-25341739

A. Abidi Saad, ORCID: http://orcid.org/0000-0001-81899473

K.O. Sebakhy, ORCID: http://orcid.org/0000-0001-66200951

Y. Bouhadda, ORCID: http://orcid.org/0000-0003-03767453

\section{ACKNOWLEDGMENTS}

The authors would like to acknowledge funding from le Ministère de l'enseignement supérieur et de la recherche scientifique de l'Algérie, and Dr. Nassar Group for Nanotechnology Research in Chemical and Petroleum Engineering Department, University of Calgary, Alberta, Canada. A special thanks to Dr. Khodja Mohamed from le Centre de Recherche et de Développement Sonatrach for helping in asphaltenes extraction. The authors would like to thank Dr. Amjad El-Qanni for helping in the preparation and characterization of nanoparticles.

\section{CONFLICT OF INTEREST}

No conflict of interest was declared by the authors.

\section{SUPPLEMENTARY MATERIALS}

Supplementary materials are available for this article at https://doi.org/10.1134/S0965544121010072 and are accessible for authorized users.

\section{OPEN ACCESS}

This article is distributed under the terms of the Creative Commons Attribution 4.0 International License (http:// 
creativecommons.org/licenses/by/4.0/), which permits unrestricted use, distribution, and reproduction in any medium, provided you give appropriate credit to the original author(s) and the source, provide a link to the Creative Commons license, and indicate if changes were made.

\section{REFERENCES}

1. Abbas, H., Hacini, M., Khodja, M., and Benaamara, C., J. Fund. Appl. Sci., 2018, vol. 10, p. 1.

https:/www.ajol.info/index.php/jfas/article/view/172032

2. Manasrah, A.D., Nassar, N.N., Appl. Energy, 2020, vol. 280 , p. 115890

https://doi.org/10.1016/j.apenergy.2020.115890

3. Hosseinpour, N., Khodadadi, A.A., Bahramian, A., and Mortazavi, Y., Langmuir, 2013, vol. 29, p 14135. https://doi.org/10.1021/la402979h

4. Franco, C.A., Nassar, N.N., Ruiz, M.A., Pereira-Almao, P., Cortés, F.B., Energy Fuels, 2013, vol. 27, p. 2899.

https://doi.org/10.1021/ef4000825

5. Manasrah, A.D., Hassan, A., and Nassar, N.N., Can. J. Chem. Eng., 2019, vol. 97, p. 2794-803.

https://doi.org/10.1002/cjce. 23574

6. Boukherissa, M., Université Paul Verlaine-Metz, 2008. https://hal.univ-lorraine.fr/tel-01752594

7. Haskett, C.E. and Tartera, M., Petrol. J. Tech., 1965, vol. 17 , p. 387. https://doi.org/10.2118/994-PA

8. Hashemi, S.I., Fazelabdolabadi, B., Moradi, S., Rashidi, A.M., Shahrabadi, A., Bagherzadeh, H., Appl. Nanosci., 2016, vol. 6, p. 71. https://doi.org/10.1007/s13204-015-0410-1

9. Mustafin, R., Manasrah, A.D., Vitale, G., Askari, R., and Nassar, N.N., J. Pet. Sci. Eng., 2020, vol. 185, p. 106569 . https://doi.org/10.1016/j.petrol.2019.106569

10. Adams, J.J., Energy Fuels, 2014, vol. 28, p. 2831. https://doi.org/10.1021/ef500282p

11. Cosultchi, A., Rossbach, P., and Hernández Calderon, I., Surf. Interface Anal., 2003, vol. 35, p. 239. https://doi.org/10.1002/sia.1516

12. Carbognani, L., Orea, M., and Fonseca, M., Energy Fuels, 1999, vol. 13, p. 351. https://doi.org/10.1021/ef9801975

13. Manasrah, D.A., Al-Mubaiyedh, U.A., Laui, T., BenMansour, R., Al-Marri, M.J., Almanassra, I.W., Abdala, A., and Atieh, M.A., Appl. Therm. Eng., 2016, vol. 107, p. 1008.

https://doi.org/10.1016/j.applthermaleng.2016.07.026

14. Nassar, N.N., Hassan, A., Carbognani, L., Lopez-Linares, F., Pereira-Almao, P., Fuel, 2012, vol. 95, p. 257. https://doi.org/10.1016/j.fuel.2011.09.022
15. Nassar, N.N., Hassan, A., and Pereira-Almao, P., Energy Fuels, 2011, vol. 25, p.,1017. https://doi.org/10.1021/ef101230g

16. Abdullah, M.M., Al-Lohedan, H.A., and Atta, A.M., RSC Adv., 2016, vol. 6, p. 59242. https://doi.org/10.1039/C6RA09651D

17. Nassar, N.N., Hassan, A., Luna, G., and Pereira-Almao, P., Catal. Today, 2013, vol. 207, p. 127. https://doi.org/10.1016/j.cattod.2012.04.054

18. Kazemzadeh, Y., Malayeri, M., Riazi, M., and Parsaei, R., J. Nat. Gas Sci. Eng., 2015, vol. 22, p. 227. https://doi.org/10.1016/j.jngse.2014.11.033

19. Shayan, N.N. and Mirzayi, B., Energy Fuels, 2015, vol. 29, p. 1397. https://doi.org/10.1021/ef502494d

20. Franco, C.A., Lozano, M.M., Acevedo, S., Nassar, N.N., and Cortés, F.B., Energy Fuels, 2016, vol. 30, p. 264. https://doi.org/10.1021/acs.energyfuels.5b02504

21. US Energy Information Administartion, Country Analysis Brief: Algeria, 2019. https:/www.eia.gov/international/analysis/country/DZA

22. Statistical Review of World Energy 2019, BP, An Unsustainable Path., 2019.

https://www.bp.com/content/dam/bp/business-sites/en/ global/corporate/pdfs/energy-economics/statistical-review/bp-stats-review-2019-full-report.pdf

23. American Society for Testing and Materials (ASTM), ASTM D6560, 2012. https://doi.org/10.1520/D6560-17

24. Fergoug, T. and Bouhadda, Y., Fuel, 2014 , vol. 115 , p. 521. https://doi.org/10.1016/j.fuel.2013.07.055

25. Schwertmann U. and Cornell, R.M., Iron Oxides in the Laboratory: Preparation and Characterization, 2008, vol. 1, John Wiley \& Sons. https://doi.org/10.1002/9783527613229

26. Bowles, J., Mineralogical Magaz., 1992, vol. 56, p. 281. https://doi.org/10.1180/minmag.1992.056.383.20

27. Manasrah, A.D., Vitale, G., Nassar, N.N., Appl. Catal. B, 2020, vol. 5, p. 264, p. 118472.

https://doi.org/10.1016/j.apcatb.2019.118472

28. Thommes, M., Kaneko, K., Neimark, A.V., Olivier, J.P., Rodriguez-Reinoso, F., Rouquerol, J., and Sing, K.S., Pure Appl. Chem., 2015, vol. 87, p. 105. https://doi.org/10.1515/pac-2014-1117

29. Toulhoat, H., Prayer, C., and Rouquet, G., Colloids Surf. A, 1994, vol. 91, p. 83. https://doi.org/10.1016/0927-7757(94)02956-3

PETROLEUM CHEMISTRY Vol. 61 No. 12021 
30. Acevedo, S., Ranaudo, M. A., García, C., Castillo, J., and Fernández, A., Energy Fuels, 2003, vol. 17, p. 257. https://doi.org/10.1021/ef020104q

31. Castro, M., de la Cruz, J.L.M., Buenrostro-Gonzalez, E., López-Ramírez, S., and Gil-Villegas, A., Fluid Ph. Equilibria, 2009, vol. 286, p. 113.

https://doi.org/10.1016/j.fluid.2009.08.009

32. Strausz, O.P., Peng, P., and Murgich, J., Energy Fuels, 2002, vol. 16, p. 22 . https://doi.org/10.1021/ef0002795

33. Angle, C.W., Long, Y., Hamza, H., and Lue, L., Fuel, 2006, vol. 85, p. 492. https://doi.org/10.1016/j.fuel.2005.08.009

34. Rana, M.S., Samano, V., Ancheyta, J., and Diaz, J., Fuel, vol. 86, p. 31. https://doi.org/10.1016/j.fuel.2006.08.004

35. Alkafeef, S.F., Algharaib, M.K., and Alajmi, A.F., J. Colloid Interface Sci., 2006, vol. 298, p. 9. https://doi.org/10.1016/j.jcis.2005.12.038
36. Pernyeszi, T., Patzkó, Á., Berkesi, O., and Dékány, I., Colloid Surface A., 1998, vol. 137, p. 384. https://doi.org/10.1016/S0927-7757(98)00214-3

37. Mohammadi, M., Akbari, M., Fakhroueian, Z., Bahramian, A., Azin, R., and Arya, S., Energy Fuels, 2011, vol. 25, p. 6 . https://doi.org/10.1021/ef2001635

38. Franco, C.A., Cortés, F.B., and Nassar, N.N., J. Colloid Interface Sci., 2014, vol. 425, p. 77. https://doi.org/10.1016/j.jcis.2014.03.051

39. Nassar, N.N., Hassan, A., and Pereira-Almao, P., J. Colloid Interface Sci., 2011, vol. 360, p. 8. https://doi.org/10.1016/j.jcis.2011.04.056

40. Nassar, N.N., Montoya, T., Franco, C.A., Cortés, F.B., and Pereira-Almao, P., Energy Fuels, 2015, vol. 29, p. 21. https://doi.org/10.1021/acs.energyfuels.5b00693

41. Franco, C.A., Nassar, N.N., Montoya, T., Ruiz, M.A., and Cortés, F.B., Energy Fuels, 2015, vol. 29, p. 21. https://doi.org/10.1021/ef502786e 